NBER WORKING PAPER SERIES

AN INTERGENERATIONAL MODEL OF DOMESTIC VIOLENCE

Robert A. Pollak

Working Paper 9099

http://www.nber.org/papers/w9099

\author{
NATIONAL BUREAU OF ECONOMIC RESEARCH \\ 1050 Massachusetts Avenue \\ Cambridge, MA 02138 \\ August 2002
}

I am grateful to the John D. and Catherine T. MacArthur Foundation and the John Simon Guggenheim Memorial Foundation for financial support, to Marla Lieberman for interesting and useful conversations, to Helen Tauchen for insightful comments, and especially to Shelly Lundberg for suggestions that have shaped and reshaped this paper. Of course I retain responsibility for the views expressed. Earlier versions of this paper were presented at Washington University in St. Louis, the University of Washington, Southern Illinois University in Carbondale, Princeton University, the Population Association of America, Northwestern University, the University of Chicago, the University of Pennsylvania, the University of Michigan, and Johns Hopkins University. The views expressed herein are those of the author and not necessarily those of the National Bureau of Economic Research.

(C) 2002 by Robert A. Pollak. All rights reserved. Short sections of text, not to exceed two paragraphs, may be quoted without explicit permission provided that full credit, including $\mathbb{C}$ notice, is given to the source. 
An Intergenerational Model of Domestic Violence

Robert A. Pollak

NBER Working Paper No. 9099

August 2002

JEL No. D1

\begin{abstract}
This paper proposes and analyzes an intergenerational model of domestic violence (IMDV) in which behavioral strategies or scripts are transmitted from parents to children.

The model rests upon three key assumptions:

* The probability that a husband will be violent depends on whether he grew up in a violent home.

* The probability that a wife will remain with a violent husband depends on whether she grew up in a violent home. homes.

* Individuals who grew up in violent homes tend to marry individuals who grew up in violent

The IMDV calls attention to three features neglected in the domestic violence literature. The first is the marriage market. If some men are more likely than others to be violent as husbands and some women are more likely than others to remain in violent marriages, then the probability that such individuals marry each other is crucial. The second neglected feature is divorce: ongoing domestic violence requires the conjunction of a husband who is violent and a wife who stays. Third, variables and policies that reduce the rate of domestic violence in the short run are likely to reduce it even further in the long run.
\end{abstract}

Robert A. Pollak

Department of Economics, Campus Box 1208

Washington University in St. Louis

205 Eliot Hall

One Brookings Drive

St. Louis, MO 63130

and NBER

Tel: 314-935-4918

Fax: 314-935-6359

pollak@olin.wustl.edu 


\section{An Intergenerational Model of Domestic Violence}

\section{Introduction}

Domestic violence is a high-profile social problem, and its prevalence and causes have been extensively discussed in both the social science literature and the popular media. The economic, social, and psychological effects of domestic (i.e., marital or spousal) violence have also received considerable attention from researchers. ${ }^{1}$ One focus of this attention has been the possible effects on children who witness violence within the family, including effects on their own tendency to perpetrate or experience domestic violence as adults. The phrase "cycle of violence" is commonplace in the literature on spouse abuse, but there have been few attempts to model the intergenerational transmission of domestic violence. This paper presents a simple model in which the prevalence of domestic violence in the long run depends upon both the intergenerational transmission of propensities for violence within families and on patterns of marriage and divorce. Its intention is to provide a prototype of more complex models that might inform discussions of violence prevention and interventions, as well as to highlight potential problems in estimating the parameters of such models and calculating the prevalence and correlates of domestic violence.

The "violence begets violence" hypothesis has many variants, ranging from assertions that abused children are more likely to become abusers themselves to concerns that viewing television violence will increase aggressive behavior among children. A principal strand in the cycle-of-violence literature examines the effects of witnessing violence between parents on the probability that children will experience violence in their own marriages, either as perpetrators or as victims. Considerable evidence has accumulated that there is a statistical relationship between violence in the parents' marriage and violence in the child's, but the intergenerational transmission mechanism is not clear. The level of marital violence will depend not only on how tendencies to commit and to tolerate violence are transmitted, but also on who marries whom, and on which marriages or relationships remain intact long enough to influence the behavior of children.

\footnotetext{
${ }^{1}$ Although I phrase the discussion of domestic violence in terms of "marriage," the analysis also applies to cohabitation.
} 
Marriage and divorce patterns are thus crucial elements of the intergenerational transmission process and of the equilibrium level of domestic violence. The selection of partners and the dissolution of violent relationships will depend on individual characteristics that may be correlated with past experiences of violence and with individual propensities for violence. The actual cycle of violence is therefore a complex phenomenon and designing effective interventions depends upon understanding the underlying transmission process. To explain the process and to focus attention on important gaps in our empirical knowledge, I propose a model of the transmission of domestic violence that explicitly recognizes the roles of marriage formation and dissolution. As in any dynamic model, the distinction between the short run and the long run is essential, but as in any intergenerational model, the long run can be very long.

The model's basic framework is one in which husbands may or may not be violent, and in which the wives of violent husbands may or may not divorce them. The model assumes that men who are raised in violent homes are more likely to be violent as adults, and that women who witness domestic violence as children are more likely to remain with an abusive spouse. I initially assume that children are affected by domestic violence only if their mothers fail to leave an abusive partner, then explore an alternative specification in which divorce is imperfectly protective. The transmission mechanism of the model is consistent with, but is not implied by, extensive evidence of a positive correlation between parental domestic violence and future involvement in an abusive relationship. In section II I discuss the empirical evidence that informs the intergenerational transmission model. A severe shortage of reliable evidence concerning the relationships among marriage, divorce, family background, and violence makes it difficult to assess alternative modeling strategies, but an explicit model helps identify data needs.

Section III provides an informal overview of the model, while section IV develops the simplest version of the model, a version with no divorce and random mating. Section V adds divorce. The addition of divorce focuses attention on the marriage market. Because ongoing domestic violence depends upon the pairing of violent men with women who will stay with them, the prevalence of domestic violence depends on the marital matching process. Section VI discusses assortative mating. In a version of a model that allows selective matching on the basis of family background characteristics associated with violence (i.e., women from violent homes are more likely to marry men from violent 
homes) I show that the equilibrium level of violence increases with positive assortative mating. ${ }^{2}$ Section VII is a brief conclusion.

\section{The Economics of Domestic Violence}

Although the literature on domestic violence is vast, the literature within economics on this topic is scant. ${ }^{3}$. Several recent papers examine the effects of spousal abuse on economic outcomes such as women's employment (Lloyd [1997], Bowlus and Seitz [2002]), or attempt to measure the overall cost to society of domestic violence (Greaves, Hankivsky, and Kingston-Riechers [1995]). Estimates of this cost depend upon the prevalence of violent marriages, which has proven very difficult to measure.

Domestic violence is believed to be underreported on surveys. In addition, reported rates are sensitive both to the definition used and the way questions are posed. In the U.S., the National Crime Victimization Survey yields estimates of annual rates violence by "intimates" that remained at about 6.5 per thousand for women and 1.2-1.8 per thousand for men during the 1980s, but these rates jumped sharply in the early 1990s when the survey was revised. Rates reported in the National Crime Victimization Survey are much lower than those implied by the National Family Violence Surveys of 1975 and 1985, which asked about specific types of violent behavior between husbands and wives and did not require that the respondent identify this behavior as a "crime." Rates of "severe" husband-towife violence of about 30 per thousand are implied by the responses to this survey, and reported rates of severe wife-to-husband violence are even higher. ${ }^{4}$ A recent Canadian data source, the Violence Against Women Survey finds that 29 percent of ever-married women and 50 percent of divorced women have been the victims of spousal abuse.

\footnotetext{
${ }^{2}$ One can make a priori arguments for negative rather than positive assortative mating and, for that matter, for negative rather than positive patterns of intergenerational transmission (e.g., arguing that those who grow up in violent homes realize how bad violence is and avoid it in choosing partners and in their own lives). Although some individuals may react in this way, the empirical evidence (e.g., Kalmuss [1994]) suggests that the intergenerational correlations are positive. Violence in the previous generation is a risk factor for violence.

${ }^{3}$ Yoshikawa and Rosman [2000] survey the domestic violence literature with an emphasis on recent work in psychology.

${ }^{4}$ Blau [1998, pp. 155-158] reports these rates and provides references for the U.S. surveys. She concludes that there is no evidence of an upward trend in domestic violence in these surveys.
} 
Most economists who have attempted to explain domestic violence rather than document its prevalence and effects have taken a game-theoretic approach. Tauchen, Witte, and Long [1991] consider a noncooperative game in which violence has both expressive and instrumental components: violence increases the husband's utility directly, and may also increase his utility indirectly through control of his wife's behavior. Their paper, the most serious sustained attempt to account for domestic violence within the framework of a bargaining model of marriage, specifies a two-stage game; whether there is violence in equilibrium depends on the level of resources controlled by each spouse and on whether the reservation utility constraint is binding (e.g., whether the wife is no better off remaining in the marriage than she would be if she left). Farmer and Tiefenthaler [1997] present a noncooperative model of domestic violence that implies that wives' income and other financial support available from outside the marriage will decrease the level of violence in intact families.

In a game-theoretic context, violence or the threat of violence can be regarded as an aspect of the "threat point" in a cooperative bargaining model or as part of a "punishment strategy" in a noncooperative game. This framework points to factors such as the wife's employment status or potential earnings, or the attractiveness of her alternatives outside the marriage, as determinants of the incidence of marital violence. Empirical studies of the wife's economic dependence and its relationship to violence, most of which have been based on small non-representative samples, have produced somewhat mixed results. However, Tauchen, Witte and Long find the expected negative relationship between violence and women's income for low- and middle-income families in their sample. Farmer and Tiefenthaler [1996] analyze the effectiveness of shelters and other services for battered women, and argue that the use of such services can be a signal of a women's unwillingness to tolerate domestic violence. Tauchen and Witte [1995] examine the effectiveness of alternative police practices (i.e., advising the couple; separating them temporarily; arresting the suspected perpetrator) in response to domestic violence calls. An interesting paper by Bloch and Rao [2002] finds patterns of wife abuse in a sample from Southern India that appear to be related to inter-household transfers, and in which transfers appear to be driven by costs and benefits.

Stevenson and Wolfers [2002] investigate the relationship between divorce law changes and domestic violence. Using state level data, they find a statistically significant relationship between the 
adoption of unilateral divorce and a decline in domestic violence. They also find that the adoption of unilateral divorce is associated with a decline in female suicide rates and in the likelihood that women will be murdered by their partners.

In this paper I ignore bargaining and rational choice in order to focus on an aspect of the empirical evidence concerning domestic violence that game-theoretic models have not addressed -- the intergenerational correlation of domestic violence. Straus [1995] asserts: "The idea that child-abusing parents were themselves victims of abuse, and that wife-beating husbands come from violent families, is now widely accepted." (Straus [1995, p. 406]). ${ }^{5}$ I leave the analysis of child abuse to a future paper; in this paper I consider only the intergenerational transmission of domestic violence.

\section{An Overview of the Model}

I propose and analyze an intergenerational model of domestic violence in which behavioral strategies or scripts are transmitted from parents to children: boys and girls learn the adult roles of husbands and wives from their fathers and mothers. ${ }^{6}$ The substantial literature on epidemiology of family violence recognizes multiple pathways of transmission, from witnessing violence in the community to being a victim of family violence. The model assumes a particular transmission pathway--witnessing domestic violence in the family of origin - though modeling a transmission mechanism that allows genetic as well as environmental components is clearly desirable. ${ }^{7}$ Marriages and divorces depend upon violence and propensities for violence in rather simple ways, but I do not model the optimizing behavior of individuals.

\footnotetext{
${ }^{5}$ Using the survey data collected by Straus and Gelles, Kalmuss [1994] provides some badly needed quantification. She reports that both marital violence and parent-child violence in family of origin are related to domestic violence. "When neither form of aggression occurred in one's childhood family, the probability of (husbandwife) aggression is $1 \% \ldots$ When only parent-child hitting occurred, the probability is increased to $3 \%$.... When only parental hitting, the probability doubles to 6\%. Finally, when both types of childhood aggression occurred, the probability of severe (husband-wife) aggression is 12\%." (p. 15)

${ }^{6}$ The model is thus broadly consistent with models of "cultural transmission" such as those proposed by CavalliSforza and Feldman [1981] and by Boyd and Richerson [1985], but the emphasis here is on intergenerational transmission within families and not on intragenerational transmission and peers.

${ }^{7}$ Wrangham and Peterson [1996] argue that the human male propensity for domestic violence has deep roots in the evolutionary history of our species, but their argument has no obvious implications for understanding differences in behavior across societies, changes in behavior within societies over time, or differences in the behavior of
} 
The model rests upon three key assumptions:

1. The probability that a husband will be violent depends on whether he grew up in a violent home.

2. The probability that a wife will remain with a violent husband depends on whether she grew up in a violent home.

3. Individuals who grew up in violent homes tend to marry individuals who grew up in violent homes; individuals who grew up in nonviolent homes tend to marry individuals who grew up in nonviolent homes.

The assumption that marital violence is asymmetric, that the husband is the perpetrator and the wife the victim, is at odds with survey evidence that wives report as many acts of violence towards their husbands as by their husbands. ${ }^{8}$ The usual assumption that men inflict most serious injuries is supported by the National Crime Victimization Survey, which reports much higher rates of violence towards women, and by relative rates of homicide by intimates. ${ }^{9}$

Heterogeneity of both men and women is central to the model: some husbands are violent, others are not; some wives divorce violent husbands, others do not. Each individual's behavior is random, but the probabilities are determined by the presence or absence of violence in the individual's family of origin. The intergenerational model of domestic violence (IMDV) relies on propensities and probabilities rather than on utility maximization and strategic behavior. It thus follows the precedent of evolutionary, demographic, and epidemiological models rather than of rational choice models. ${ }^{10}$ Avoiding the complications of rational choice, I focus on other complications. A thoroughgoing rational choice version of the IMDV would require allowing individuals to make choices regarding marriage, fertility, violence, and divorce. Like the IMDV, however, any satisfactory model of domestic violence must recognize the role of parents' behavior in shaping and molding their children's preferences. $^{11}$

individuals within a society.

${ }^{8}$ Straus and Gelles [1986]; Straus [1997].

${ }^{9}$ Bachman and Saltzman [1995].

${ }^{10}$ Unlike evolutionary games in which fitness is density dependent, I assume that survival probabilities and reproductive success are independent of the composition of the population and identical for all individuals.

${ }^{11}$ On the transmission of preferences, see Pollak [1976], Becker [1992], Pollak and Watkins [1993], and Becker [1996]. 
The basic structure of the IMDV can be described with the use of a time line. We begin in period $t$ with an initial vector showing the number of men and the number of women of each type in the population where types are defined in terms of sex and home environment (violent/nonviolent). The model specifies a sequence of five stages that defines a mapping of the population by type in period $t$ into the population by type in period $t+1$ :

(1) marriages

(2) births

(3) signals indicating whether the husband will be violent

(4) divorce/nondivorce

(5) violence/nonviolence.

\section{Time Line}

marriages births signals divorce violence marriages

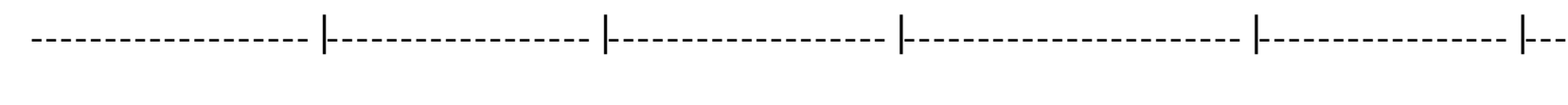

Period $\mathrm{t}$

Period $t+1$

This sequence reflects two simplifying assumptions. First, realized violence affects neither marriage nor fertility. If signals regarding propensities for violence are broadcast during courtship (e.g., if violence in the families of origin of potential spouses are observable), we might expect both assortative mating and systematic differences in marriage and fertility rates between different types of individuals. The timing assumptions of the model preclude this: realized violence occurs too late to affect marriage or fertility. Second, I begin with the assumption that divorce occurs, if at all, before violence has occurred (e.g., because divorce is triggered by the signal that violence will occur rather than by the occurrence of violence). This assumption implies that divorce is "fully protective" because divorce prevents children from witnessing domestic violence. I then examine the consequences of relaxing the assumption that divorce is fully protective of children.

IV. The Simplest IMDV: No Divorce and Random Mating 
I begin with notation to characterize the population distribution in period t:

$\pi_{F t}=$ the fraction of women who grew up in violent homes in period $\mathrm{t}$

$\pi_{M t}=$ the fraction of men who grew up in violent homes in period $\mathrm{t}$

I assume that propensities for violence depend upon the type of home (violent or nonviolent) in which the husband grew up:

$p_{v}=$ the probability that a man will be violent if he grew up in a violent home

$p_{\bar{v}}=$ the probability that a man will be violent if he grew up in a nonviolent home

These probabilities are crucial parameters of the IMDV. Not surprisingly, the equilibrium level of violence is increasing in both $p$ parameters. I assume $p_{\bar{v}} \leq p_{v}$. Intergenerational transmission of a propensity toward violence corresponds to the strict inequality (i.e., $p_{\bar{v}}<p_{v}$ ), but the polar case in which $p_{\bar{v}}=p_{v}$ provides a benchmark.

The simplest version of the IMDV assumes that mating is random with respect to the family background (violent/nonviolent) of men and women, and that marriages cannot be dissolved. I begin by calculating the fraction of violent homes in period $t+1$, assuming random mating and no divorce:

$$
\pi_{t+1}=p_{v} \pi_{F t} \pi_{M t}+p_{\nabla} \pi_{F t}\left(1-\pi_{M t}\right)+p_{v}\left(1-\pi_{F t}\right) \pi_{M t}+p_{\nabla}\left(1-\pi_{F t}\right)\left(1-\pi_{M t}\right)
$$

Since $\pi_{F t}=\pi_{M t}=\pi_{t}$, (1a) reduces to

$$
\pi_{t+1}=p_{v} \pi_{t}+p_{\nabla}\left(1-\pi_{t}\right)
$$

and we can rewrite (1b) as

$$
\text { (1c) } \pi_{t+1}=p_{\bar{v}}+\left(p_{v}-p_{\nabla}\right) \pi_{t} \text {. }
$$


In a steady state, $\pi=\pi_{t}=\pi_{t+1}$, so that (1b) implies

(2a) $\quad \pi=p_{v} \pi+p_{\bar{v}}(1-\pi)$.

We can investigate the existence, uniqueness, and comparative statics properties of the long-run equilibrium by solving (2a) for $\pi$ as a function of $p_{v}$ and $p_{\sigma}$

$$
\pi=p_{\bar{v}} /\left[1-\left(p_{v}-p_{\bar{v}}\right)\right]
$$

Clearly, this simple version of the IMDV has a unique long-run equilibrium. Furthermore, it is straightforward to show from equation (3) that the equilibrium value of $\pi$ is an increasing function of $p_{v}$ and of $p_{\nabla}$. Equation (2) implies that $\pi$ is a weighted average of $p_{\nabla}$ and $p_{v}$ and, hence,

$$
p_{v} \leq \pi \leq p_{v}
$$

As $p_{\bar{v}}$ increases from 0 to $p_{v}$, the equilibrium value of $\pi$ increases from 0 to $p_{v}$. As $p_{v}$ increases from $p_{\sigma}$ to 1 , the equilibrium value of $\pi$ increases from $p_{\sigma}$ to 1 .

In versions of the IMDV with divorce and assortative mating, I use a different approach to investigate existence, uniqueness, and comparative statics. In those versions of the IMDV, the equations analogous to (2a) are nonlinear and I rely on the implicit function theorem rather than explicitly solving for the equilibrium value of $\pi$. With no divorce and random mating, the analogue of the implicit function approach rearranges ( $2 \mathrm{a}$ ) by moving $\pi$ to the right-hand side, defines a function $\mathrm{G}(\pi)$ by

(2b) $G(\pi)=p_{v} \pi+p_{\bar{v}}(1-\pi)-\pi$

and observes that the equilibrium level of $\pi$ is implicitly defined by the equation

(2c) $G\left(\pi^{*}\right)=0$.

Differences between the long-run and short-run effects of a change in the parameters on the level of violence can be easily seen in this simple model. For example, an increase in the probability that a man from a violent home will be violent will have a smaller impact on the rate of violence in the next 
period (differentiate (1b) with respect to $p_{v}$ ), than it will have on the equilibrium level of violence (from (3)).

The dynamics are also straightforward. Equation (1c) is the familiar nonhomogeneous linear difference equation ${ }^{12}$ whose solution is

$$
\pi_{t}=\left(p_{v}-p_{\bar{v}}\right)^{t} \pi_{0}+p_{\bar{v}} \frac{\left[1-\left(p_{v}-p_{\bar{v}}\right)^{t}\right]}{\left[1-\left(p_{v}-p_{\bar{v}}\right)\right]} .
$$

As t increases, $\left(p_{v}-p_{\nabla}\right)^{t}$ approaches 0 and $\pi_{t}$ converges to the equilibrium (3).

Three degenerate cases provide benchmarks:

Case 1. If $p_{\bar{\sigma}}=p_{v}$, then $\pi=p_{\nabla}=p_{v}$. That is, if the probability that a man will be violent is the same regardless of whether he comes from a violent or a nonviolent home, then the equilibrium is equal to this common probability.

Case 2. If $p_{v}=1$ and $p_{v} \neq 0$, then $\pi=1$. That is, if all men from violent homes are violent and some men from nonviolent homes are violent then in equilibrium all men are violent.

Case 3. If $p_{\bar{v}}=0$ and $p_{v} \neq 1$, then $\pi=0$. That is, if men from nonviolent homes are never violent and not all men from violent homes are violent, then in equilibrium violence disappears. ${ }^{13}$

A diagram illustrates the long-run equilibria corresponding to various parameter combinations. We plot $p_{v}$ on the $\mathrm{x}$-axis and $p_{\nabla}$ on the $\mathrm{y}$-axis; points below the $45^{\circ}$ ray correspond to parameter combinations satisfying the condition that $p_{\bar{v}}<p_{v}$. The equilibrium level of violence is constant along the plotted curves, each of which is a straight line radiating from the point $\left(p_{v}, p_{\bar{v}}\right)=(1,0)$. The level of violence corresponding to each curve can be inferred from the values of $p_{v}$ and $p_{\bar{v}}$ corresponding to the

\footnotetext{
${ }^{12}$ See Luenberger [1979, pp. 19-22].

${ }^{13}$ If $p_{v}=1$ and $p_{\bar{v}}=0$, then equation (1c) implies a neutral equilibrium in which $\pi_{t+1}=\pi_{t}=\pi_{0}$ regardless of the initial value of $\pi_{0}$.
} 
intersection of the curve with the $45^{\circ}$ ray from the origin; along the $45^{\circ}$ ray, $p_{v}=p_{\nabla}$ and the equilibrium value of $\pi$ is equal to their common value. ${ }^{14}$

Figure 1 goes about here

\section{Divorce}

I next add divorce to the simplest model by assuming that women who grew up in nonviolent homes are less likely to stay with violent husbands than are women from violent homes. Allowing divorce to depend on family background makes the model much more complex by requiring two additional parameters and destroying linearity. In certain degenerate cases, however, the model with divorce becomes as transparent as the model without divorce. I begin by assuming that divorce is "fully protective" in the sense that children who grow up in single parent families have the same propensities to violence and to divorce as children who grow up in nonviolent two parent families.

Notation for staying with a violence husband is more convenient that notation for leaving:

$s_{v}=$ the probability that a women will stay married to a violent husband if she grew up in a violent home, and $s_{\sigma}=$ the probability that a woman will stay married to a violent husband if she grew up in a nonviolent home.

I assume $s_{\bar{v}} \leq s_{v}$. An intergenerational transmission of a propensity for women to stay with violent husbands corresponds to the strict inequality (i.e., $s_{\bar{v}}<s_{v}$ ), but the polar case in which $s_{\bar{v}}=s_{v}$

provides a benchmark. ${ }^{15}$ With the introduction of divorce, the probability that a man has a propensity to be violent and the probability that an observed marriage will be violent are no longer equal. Empirical studies of domestic violence and its effects must recognize that this selectivity implies that observed violent marriages constitute a population that differs systematically in terms of other characteristics as

\footnotetext{
${ }^{14}$ I am grateful to Helen Tauchen for suggesting this figure.

${ }^{15}$ I do not introduce notation for the probabilities that women from each type of home will stay married to nonviolent husbands, because these probabilities play no role in the analysis.
} 
well, and many of these other characteristics will influence the experiences and characteristics of children. ${ }^{16}$

We now need to distinguish among four types of marriages, depending on the type of home in which the husband grew up and the type of home in which the wife grew up. For each type, we have a probability that the husband will be violent and, for each type, a probability that the wife will stay married if her husband is violent. Hence, given the fraction of violent homes in period $t$, we can calculate the fraction of violent homes in period $t+1$ :

$$
\pi_{t+1}=s_{v} p_{v} \pi_{F t} \pi_{M t}+s_{v} p_{\nabla} \pi_{F t}\left(1-\pi_{M t}\right)+s_{\nabla} p_{v}\left(1-\pi_{F t}\right) \pi_{M t}+s_{\nabla} p_{\nabla}\left(1-\pi_{F t}\right)\left(1-\pi_{M t}\right)
$$

Recognizing that $\pi_{F t}=\pi_{M t}=\pi_{t}$, (5a) can be rewritten as

$$
\pi_{t+1}=s_{v} p_{v} \pi_{t}^{2}+s_{v} p_{\nabla} \pi_{t}\left(1-\pi_{t}\right)+s_{\nabla} p_{v}\left(1-\pi_{t}\right) \pi_{t}+s_{\nabla} p_{\nabla}\left(1-\pi_{t}\right)^{2}
$$

Moving $\pi_{t+1}$ to the right hand side of (5b) and rewriting it in terms of the equilibrium value of $\pi$, the equilibrium condition becomes

$$
G(\pi)=s_{v} p_{v} \pi^{2}+s_{v} p_{\bar{v}} \pi(1-\pi)+s_{\bar{v}} p_{v} \pi(1-\pi)+s_{\bar{v}} p_{\bar{v}}(1-\pi)^{2}-\pi=0
$$

Equation (5b) implies that $\pi_{t+1}$ is a weighted average of the four factors $\left\{s_{v} p_{v}, s_{v} p_{\bar{v}}, s_{\bar{v}} p_{v}, s_{\bar{v}} p_{\bar{v}}\right\}$. Under our assumptions, this implies

$$
s_{\nabla} p_{\nabla} \leq \pi_{t+1} \leq s_{v} p_{v}
$$

The existence of an equilibrium value of $\pi$-- that is, a value $\pi^{*}, 0 \leq \pi^{*} \leq 1$, for which $G\left(\pi^{*}\right)=0$--follows immediately from the continuity of the function $G(\cdot)$, the intermediate value theorem, and the observations that

\footnotetext{
${ }^{16}$ Bowlus and Seitz [2002] find that domestic violence plays an important role in the divorce decision: the divorce rate of women in the Canadian Violence Against Women Survey who were not abused was 15\%, while the divorce
} 


$$
\begin{aligned}
& G(0)=s_{\bar{v}} p_{\bar{v}}>0, \quad \text { and } \\
& G(1)=s_{v} p_{v}-1<0 .
\end{aligned}
$$

Figure 2 illustrates the argument for existence and the argument for uniqueness (below). ${ }^{17}$

To establish uniqueness, we appeal to the fact that the function $G($.$) is quadratic. This fact, in$ conjunction with $G(0)>0$ and $G(1)<0$, implies that the function $G($.$) has exactly one 0$ in the interval $[0,1]$. This argument also implies that $G($.$) is downward sloping at the equilibrium, \pi^{*}$. (The argument does not imply that the function $G($.$) is monotonically decreasing on the interval [0,1]$; the conclusion we require is that $G($.$) crosses the x-axis exactly once on the interval [0,1]$ and is downward sloping when it crosses the axis.)

Figure 2 goes about here

The quadratic formula, which I present in the Appendix, yields an opaque expression for the equilibrium value of $\pi$ in terms of the four parameters $\left\{p_{v}, p_{\bar{v}}, s_{v}, s_{\bar{v}}\right\} .{ }^{18}$ The model with divorce becomes transparent in three special cases.

Case 1. Suppose $s_{v}=s_{\sigma}=s$, so the probability that a wife will stay married to a violent husband is independent of whether she grew up in a violent or a nonviolent home. In this case, because $p_{v}$ and $p_{v}$ are always multiplied by the common value of $s$ and because $s$ appears nowhere else, we can attach the common "staying probability" to $p_{v}$ and $p_{\bar{v}}$; using the newly defined parameters,

$$
p_{v}^{*}=s p_{v}
$$

rate for women who reported being severely abused in their first marriage was $75 \%$.

${ }^{17}$ This argument ignores the two boundary cases (i.e., $s_{\bar{v}} p_{\bar{v}}=0$ and $s_{v} p_{v}=1$ ) and assumes that the strict inequalities hold.

${ }^{18}$ Figure 2 shows a quadratic that decreases monotonically on the interval [0,1], but the argument does not depend on this assumption and is consistent with any quadratic satisfying our end point conditions. It is not difficult to show that $\mathrm{G}(\pi)$ must be decreasing at $\pi=0$ and at the equilibrium $\pi=\pi^{*}$. It may, however, reach a minimum on the interval $\left(\pi^{*}, 1\right)$ and be increasing at $\pi=1$. 


$$
p_{\sigma}^{*}=s p_{\bar{\nabla}},
$$

the model with common divorce rates becomes formally identical to the reparameterized model without divorce. Using the earlier argument, we have an expression for the equilibrium level of violence that is analogous to equation (3):

$$
\pi=\frac{p_{\bar{v}}^{*}}{1-\left(p_{\bar{v}}^{*}-p_{v}^{*}\right)} .
$$

Not surprisingly, divorce prevents the transmission of some violence under our assumptions, and so reduces the equilibrium level of violence.

Case 2. Suppose $p_{v}=p_{v}=p$, so that the probability that a man will be violent is independent of whether he grew up in a violent home. In this case intergenerational transmission takes place only through the propensity of women to remain with violent husbands. We can attach the common "violence probability" to $s_{v}$ and $s_{\bar{v}}$ and, rewrite (5b) using the newly defined parameters,

$$
\begin{aligned}
& s_{v}^{*}=s_{v} p \\
& s_{\bar{v}}^{*}=s_{\nabla} p
\end{aligned}
$$

Solving for the equilibrium level of violence yields

$$
\pi=\frac{s_{\bar{v}}^{*}}{1-\left(s_{v}^{*}-s_{\bar{v}}^{*}\right)} .
$$

Case 3. Suppose $s_{\bar{v}}=0$, so that women who grew up in nonviolent homes will not stay married to violent husbands. In this case, the equilibrium condition (6) reduces to

$$
\pi=p_{v}^{*} \pi^{2}+p_{\bar{\nabla}}^{*}(1-\pi) \pi, \text { where } p_{v}^{*}=s_{v} p_{v} \text { and } p_{\bar{v}}^{*}=s_{v} p_{\bar{v}}
$$

One solution is clearly $\pi=0$, the case in which violence disappears. In fact, this is the only admissible solution unless other parameters also assume boundary values. To see this, notice that if $\pi \neq 0$, we can divide through by $\pi$ and the equilibrium condition becomes 


$$
1=p_{v}^{*} \pi+p_{\nabla}^{*}(1-\pi)
$$

That is, a weighted average of $p_{v}^{*}$ and $p_{\sigma}^{*}$ must equal unity. If $\pi=1$, this implies $p_{v}^{*}=1$, and, hence, $s_{v}=p_{v}=1$ (i.e., men who grew up in violent homes are always violent, and women who grew up in violent homes always stay married to violent husbands). If $\pi \neq 1$, this is possible only if both $p_{v}^{*}$ and $p_{\sigma}^{*}$ equal unity, so that we must have both $s_{v}=p_{v}=1$, and $p_{v}=1$ (the additional requirement implies that men who grew up in nonviolent homes are always violent.)

I now relax the assumption that divorce is fully protective for children born into violent families and assume instead that divorce is only partially protective. This may be the case if some violence precedes the divorce or if propensities to commit or to tolerate violence are transmitted from parents to children by some mechanism other than the actual observation of violence. More precisely, I assume that for a child born into a violent family, divorce is fully protective with probability $\gamma$ and not at all protective with probability $(1-\gamma)$. It is convenient to define a parameter $\omega$ to represent the fraction of children who possess the propensities characteristic of children who grew up in violent homes. Thus $\omega$ includes both children who grew up in violent homes and children who left violent homes but for whom divorce was not protective. With this convention the equilibrium level of domestic violence, $\pi$, will be less than the equilibrium level of $\omega$; women who divorce will not themselves be victims of violence, but with probability $(1-\gamma)$ their children will carry the same propensities as children who grew up in violent homes. ${ }^{19}$ Two comments are in order: (i) Although I have assumed that transmission is based on learning and imitation, if the transmission process includes genetic components, then divorce will not be fully protective. (ii) The assumption that divorce is equally protective (or equally unprotective) for boys and their propensity to perpetrate violence and for girls and their propensity to tolerate violence is only a convenient simplification.

When divorce is not fully protective, the analogue of equation (5b) is obtained by adding to each of the four terms an additional term corresponding to the children who left violent homes but who

\footnotetext{
${ }^{19}$ I continue to assume that divorce protects women from experiencing domestic violence, ignoring the possibility that their ex-husbands will pursue them. Wilson and Daly [1993] present data showing that spousal homicide is more female-biased in estranged than in co-residing married couples.
} 
have the same propensities to perpetrate and tolerate violence as children who grew up in violent homes. Thus, the analogue of equation ( $5 b)$ is given by

$$
\omega_{t+1}=s_{v}^{* *} p_{v} \omega_{t}^{2}+s_{v}^{* *} p_{\bar{v}} \omega_{t}\left(1-\omega_{t}\right)+s_{\bar{v}}^{* *} p_{v}\left(1-\omega_{t}\right) \omega_{t}+s_{\bar{v}}^{* *} p_{\bar{v}}\left(1-\omega_{t}\right)^{2}
$$

where $s_{v}^{* *}$ and $s_{\bar{v}}^{* *}$ are given by

$$
s_{v}^{* *}=s_{v}+(1-\gamma)\left(1-s_{v}\right) \quad \text { and } \quad s_{\bar{v}}^{* * *}=s_{\bar{v}}+(1-\gamma)\left(1-s_{\bar{v}}\right) \text {. }
$$

The formal properties of the model are unaffected by relaxing the assumption that divorce is not fully protective. If divorce is not at all protective, then the transmission process is equivalent to that in the model with no divorce. The equilibrium level of violence, however, is not the same in the two models because women who divorce are not themselves victims of domestic violence. The equilibrium level of domestic violence can be calculated directly from the equilibrium level of $\omega$ :

$$
\pi=s_{v} p_{v} \omega^{2}+s_{v} p_{\bar{v}} \omega(1-\omega)+s_{\bar{v}} p_{v}(1-\omega) \omega+s_{\bar{v}} p_{\bar{v}}(1-\omega)^{2}
$$

\section{Assortative Mating}

I now relax the assumption that women from violent and nonviolent homes are equally likely to marry men who grew up in violent homes and investigate the implications of assortative mating. A positive association between the family backgrounds of husbands and wives, and thus between their propensities to commit and to tolerate violence, may result from a correlation between violence propensities and other characteristics that affect matching, such as gender role attitudes, or because of signals sent and received during courtship. To generalize the analysis from random mating to assortative mating and obtain strong results requires specific functional form assumptions. ${ }^{20}$ I consider a particularly tractable one-parameter specification of assortative mating.

\footnotetext{
${ }^{20}$ A similar situation arises in generalizing the one-sex model of classical stable population theory, which is inherently a linear model, to a two-sex model, which is inherently nonlinear. Strong results in the generalized model require specific functional form assumptions; see Pollak [1990].
} 
Suppose the marriage market is composed of three distinct submarkets—a "mixed" or "combined" submarket that contains both individuals who grew up in violent homes and individuals who grew up in nonviolent homes, and two "pure" submarkets, one composed only of individuals who grew up in violent homes and the other composed only of individuals who grew up in nonviolent homes. I limit myself to the special case in which the same fraction, $(1-\sigma)$, of individuals from violent and from nonviolent homes enter the combined marriage market. Within the combined submarket, I assume random mating. We can think of the allocation of individuals to submarkets as a two stage procedure. First select an individual at random from the population; with probability $\pi_{t}$ the individual will be from a violent home and with probability $1-\pi_{t}$ from a nonviolent home. Second, assign the randomly selected individual to the appropriate pure submarket with probability $\sigma$ and to the combined submarket with probability $(1-\sigma)$.

Characterizing marriages by the type of home (violent or nonviolent) in which the husband and the wife grew up, we distinguish among four types of marriages. In the two pure submarkets, however, only one of the four types is represented, while in the combined submarket all four types are represented. To establish the existence and uniqueness of equilibrium in the IMDV with divorce and assortative mating, we calculate the fraction of violent homes in period $t+1$ :

$$
\begin{aligned}
& \pi_{t+1}=\sigma s_{v} p_{v} \pi_{t}+\sigma s_{\bar{v}} p_{\bar{v}}\left(1-\pi_{t}\right)+(1-\sigma) s_{v} p_{v} \pi_{t}^{2}+(1-\sigma) s_{v} p_{\bar{v}} \pi_{t}\left(1-\pi_{t}\right) \\
& +(1-\sigma) s_{\bar{v}} p_{v} \pi_{t}\left(1-\pi_{t}\right)+(1-\sigma) s_{\bar{v}} p_{\bar{v}}\left(1-\pi_{t}\right)^{2}
\end{aligned}
$$

The first two terms represent the contributions of the two pure submarkets; the last four terms, the contribution of the combined submarket. 
Two polar cases are transparent. When $\sigma=0$, the two pure submarkets disappear and the model reduces to the random mating model discussed in section V. When $\sigma=1$, the mixed or combined submarket disappears and the model reduces to "pure assortative mating" - individuals from violent homes marry individuals from violent homes, and individuals from nonviolent homes marry individuals from nonviolent homes. With pure assortative mating, equation (10a) becomes

(11b) $\pi_{t+1}=s_{v} p_{v} \pi_{t}+s_{\nabla} p_{\bar{v}}\left(1-\pi_{t}\right)$

which is linear in $\pi$. The model with pure assortative mating is isomorphic to the model with random mating and no divorce discussed in section IV. The long-run equilibrium is given by

$$
\pi=\frac{r_{\bar{v}}}{1-\left(r_{v}-r_{\bar{v}}\right)}
$$

where $r_{v}=s_{v} p_{v}$ and $r_{v}=s_{v} p_{v}$ and the dynamics are given by an equation analogous to (4). A diagram analogous to figure 1 illustrates the long-run equilibria corresponding to various combinations of $r_{v}$ and $r_{\bar{v}}$.

Returning to the general case, we establish the existence of equilibrium as we did in the case of random mating, by moving $\pi_{t+1}$ to the right hand side of (12a), and replacing $\pi_{t+1}$ and $\pi_{t}$ by the equilibrium value, $\pi$. The equilibrium condition becomes

$$
\begin{aligned}
& G(\pi, \sigma)=\sigma s_{v} p_{v} \pi+\sigma s_{\bar{v}} p_{\bar{v}}(1-\pi)+(1-\sigma) s_{v} p_{v} \pi^{2}+(1-\sigma) s_{v} p_{\bar{v}} \pi(1-\pi) \\
& +(1-\sigma) s_{\bar{v}} p_{v} \pi(1-\pi)+(1-\sigma) s_{\bar{v}} p_{\bar{v}}(1-\pi)^{2}-\pi=0
\end{aligned}
$$

We observe that, as with random mating,

$$
\begin{aligned}
& G(0, \sigma)=s_{\sigma} p_{\sigma}>0 \text { and } \\
& G(1, \sigma)=s_{v} p_{v}-1<0 .
\end{aligned}
$$


The existence of an equilibrium value of $\pi$ follows immediately from the continuity of the function $G(\cdot, \sigma)$ and the intermediate value theorem. To establish uniqueness, we observe that with our oneparameter specification of assortative mating the function $G(\cdot, \sigma)$ is quadratic. Hence, the argument from the random mating case applies here as well.

The greater the degree of assortative mating (i.e., the greater the value of $\sigma$ ), the greater the equilibrium level of domestic violence. This comparative statics result follows from the implicit function theorem. Since $G(\pi, \sigma)=0$, we have

$$
\pi=g(\sigma)
$$

and

$$
\frac{d \pi}{d \sigma}=\frac{d g(\sigma)}{d \sigma}=-\frac{\frac{\partial G(\pi, \sigma)}{\partial \sigma}}{\frac{\partial G(\pi, \sigma)}{\partial \pi}}
$$

The uniqueness argument implies that the function $G(\pi, \sigma)$ crosses the x-axis exactly once on the interval $[0,1]$ and that it is downward sloping at the point $\pi *$ at which $G\left(\pi^{*}, \sigma\right)=0$; hence

$$
\frac{\partial G\left(\pi^{*}, \sigma\right)}{\partial \pi}<0 .
$$

Thus, the sign of $d \pi / d \sigma$ is the same as the sign of $\partial G(\pi, \sigma) / \partial \sigma$. Differentiating $G(\pi, \sigma)$ with respect to $\sigma$ and combining terms we obtain

$$
\begin{aligned}
\frac{\partial G(\pi, \sigma)}{\partial \sigma} & =\left[s_{v} p_{v}-s_{v} p_{\bar{v}}-s_{\bar{v}} p_{v}+s_{\bar{v}} p_{\bar{v}}\right] \pi(1-\pi) \\
& =\left(s_{v}-s_{\bar{v}}\right)\left(p_{v}-p_{\bar{v}}\right) \pi(1-\pi)
\end{aligned}
$$

The first two factors are positive because of our assumptions about intergenerational transmission (e.g., men from violent homes are more likely to be violent than men from nonviolent homes); the third and fourth factors are positive because $\pi$ lies between 0 and 1 . Hence 


$$
\frac{\partial G(\pi, \sigma)}{\partial \sigma}>0
$$

and so

$$
\frac{d \pi}{d \sigma}=\frac{d g(\sigma)}{d \sigma}>0
$$

QED.

Thus, assortative mating on aspects of family background that are related to individual propensities to perpetrate or tolerate violence will increase the equilibrium level of violence.

VII. Conclusion

The IMDV formalizes the commonplace notion of an intergenerational "cycle of domestic violence" providing a highly stylized representation of domestic violence and its transmission. It treats intergenerational transmission as stochastic -- witnessing domestic violence in the family of origin is not an inexorable precursor of violence, but it does increase the likelihood of violence. The motivation for violence is purely expressive and not at all instrumental: violence and threats of violence are not manifestations of power used to enforce allocational or distributional outcomes. The IMDV is thus consistent with the "culture of violence" analysis emphasized by Straus and Gelles [1995].

The IMDV is less consistent with recent bargaining models of marriage, including those developed in Lundberg and Pollak [1993, 1994, 1996]. Lundberg and Pollak [1993] develops a cooperative model with an internal (noncooperative) threat point and suggests that incorporating domestic violence into this type of bargaining model could shed light on both distribution within marriage and the incidence of domestic violence. But incorporating domestic violence into a bargaining model of marriage is difficult for much the same reasons that incorporating strikes into models of union-firm bargaining is difficult: in the absence of mistakes or private information, neither domestic violence nor strikes will occur in equilibrium. $^{21}$ 
Although the IMDV is not a rational choice model, it could easily be modified to allow maximizing behavior at the key decision points—-marriage, fertility, divorce, and violence — while maintaining the emphasis on intergenerational linkages. Economic factors, policy variables, and social and cultural factors might influence domestic violence through the probabilities that are the parameters of the model. For example, economic factors such as earnings and the availability of welfare benefits might influence domestic violence primarily through their effect on marriage and divorce probabilities. ${ }^{22}$ The model may thus cast some light on the effect on domestic violence of welfare reform policies that create incentives to keep marriages together because such policies are likely to increase the probability that violent as well as nonviolent marriages remain intact. Policy variables, such as the way police respond to domestic violence complaints and the way courts treat domestic violence cases, might influence domestic violence primarily through their direct effect on violence probabilities. The social and cultural acceptability of violence might also influence violence probabilities and probabilities of divorce in the event of violence.

The IMDV calls attention to three features neglected in the domestic violence literature. The first is the marriage market. If some men are more likely than others to be violent as husbands and some women are more likely than others to remain in violent marriages, then the probability that such individuals marry each other is crucial. Furthermore, to the extent that these assortative mating results generalize to more complex specifications, the equilibrium level of domestic violence increases monotonically with assortative mating on the basis of violence or on characteristics related to violence in families of origin. The second neglected feature is divorce: ongoing domestic violence requires the conjunction of a husband who is violent and a wife who stays. Appropriate measures of the prevalence and correlates of domestic violence depend on whether the population at risk is defined as couples who entered marriage at a particular date or as married couples at a particular date. ${ }^{23}$ Hence, recognition of the importance of the marriage market and divorce is crucial to calculating such measures. Third, variables and policies that reduce the rate of domestic violence in the short run are likely to reduce it even further in the long run. Amplification of the impact effect follows from the dynamics of intergenerational transmission: a permanent change in an economic or policy variable that reduces the

\footnotetext{
${ }^{21}$ Kennan [1986] and Cramton and Tracy [1992] discuss strikes.

${ }^{22}$ It would be more difficult to generalize the model to include an intergenerational transmission mechanism for earnings, and to allow earnings or earnings prospects to play a role in the marriage market.

${ }^{23}$ Similar analytic issues arise in thinking about the correlates of welfare or unemployment; the population entering
} 
rate of violence in period $t$ reduces it even further in period $t+1$ and beyond because it reduces the fraction of individuals who grew up in violent families.

welfare at a particular date looks very different from the population of welfare recipients. 


\section{References}

Bachman, Ronet and Linda E. Saltzman. Violence Against Women: A National Crime Victimization Survey Report. U.S. Department of Justice, January 1994.

Becker, Gary S., "Habits, Addictions, and Traditions," Kyklos, Vol. 45, No. 3, (1992), 327-345. Reprinted as Becker [1996, Ch. 6].

Becker, Gary S. Accounting for Tastes, Cambridge: Harvard University Press, 1996.

Blau, Francine D., "Trends in the Well-Being of American Women, 1970-1995," Journal of Economic Literature, Vol. XXXVI, No. 1, (March 1998), 112-165.

Bloch, Francis and Vijayendra Rao, "Terror as a Bargaining Instrument: A Case-Study of" Dowry Violence in Rural India," forthcoming, American Economic Review, 2002.

Boyd, R. and Richerson, P. J. Culture and the Evolutionary Process. Chicago: University of Chicago Press, 1985.

Bowlus, Audra and Shannon Seitz, "Domestic Employment and Divorce," June 2002.

Cramton, Peter C., and Joseph S. Tracy, "Strikes and Holdouts in Wage Bargaining: Theory and Data," American Economic Review, Vol. 82, No. 1 (March 1992), 100-121.

Cavalli-Sforza, L.L. and M.W. Feldman, Cultural Transmission and Evolution: A Quantitative Approach, Princeton: Princeton University Press, 1981.

Cherlin, Andrew J., Public and Private Families, New York: McGraw Hill, 1996.

Farmer, Amy and Jill Tiefenthaler, "Domestic Violence: The Value of Services as Signals," American Economic Review, Vol. 86, No. 2, (May 1996), 274-279.

Farmer, Amy and Jill Tiefenthaler, “An Economic Analysis of Domestic Violence," Review of Social Economy, Vol. 55, No. 3, (Fall 1997), 337-358.

Greaves, Lorraine, Olena Hankivsky, and JoAnn Kingston-Riechers. Selected Estimates of the Costs of Violence Against Women. Centre for Research on Violence Against Women and Children, 1995.

Kalmuss, Debra, “The Intergenerational Transmission of Marital Aggression ” Journal of Marriage and the Family, Feb. 1994, 11-19.

Kennan, John, "The Economics of Strikes," in Orley C. Ashenfelter and Richard Layard, eds., Handbook of Labor Economics, Vol. 2. Amsterdam: North-Holland Publishing Company, 1986, 1091-1137.

Lloyd, Susan, "The Effects of Domestic Violence on Women's Employment," Law and Policy, Vol. 9, No. 2 (April, 1997), 139-167. 
Luenberger, David, Introduction to Dynamic Systems: Theory, Models, and Applications, New York: John Wiley \& Sons, 1979.

Lundberg, Shelly and Robert A. Pollak, "Separate Spheres Bargaining and the Marriage Market," Journal of Political Economy, Vol. 101, No. 6, (December 1993), 988-1010.

Lundberg, Shelly and Robert A. Pollak, "Noncooperative Bargaining Models of Marriage," American Economic Review, Vol. 84, No. 2, (May 1994), 132-137.

Lundberg, Shelly and Robert A. Pollak, "Bargaining and Distribution in Marriage," Journal of Economic Perspectives, Vol. 10, No. 4, (fall 1996), 139-158.

Pollak, Robert A., "Interdependent Preferences," American Economic Review Vol. 66, No. 3 (June 1976), 309-320.

Pollak, Robert A., "Two-Sex Demographic Models," Journal of Political Economy, Vol. 98, No. 2, (April, 1990), 399-420.

Pollak, Robert A. and Susan Cotts Watkins, "Cultural and Economic Approaches to Fertility: Proper Marriage or Mésalliance?” Population and Development Review, Vol. 19, No. 3, (September 1993), 467-496.

Straus, Murray A., "Physical Assaults by Women Partners: A Major Social Problem," in Mary Roth Walsh, ed., Women, Men, and Gender: Ongoing Debates. New Haven: Yale University Press, 1997, 210-221.

Straus, Murray A. and Richard J. Gelles, Physical Violence in American Families: Risk Factors and Adaptations to Violence in 8,145 Families, New Brunswick: Transaction Publishers. 1990.

Straus, Murray A. and Richard J. Gelles, "Societal Change and Change in Family Violence from 1975 to 1985 as Revealed by Two National Surveys," Journal of Marriage and the Family, Vol. 48 (1986), 465-479.

Stevenson, Betsey and Justin Wolfers, "'Til Death Do Us Part: The Effects of Divorce Laws on Suicide, Domestic Violence and Intimate Homicide," mimeo, Stanford University, 2002.

Tauchen, Helen V., Ann Dryden Witte, and Sharon K. Long, "Violence in the Family: A Non-random Affair," International Economic Review, Vol. 32, No. 2, (May 1991), 491-511.

Tauchen, Helen V. and Ann Dryden Witte, “The Dynamics of Domestic Violence," American Economic Review, Vol. 85, No. 2, (May 1995), 414-418.

Wilson, Margo and Martin Daly, "Spousal Homicide Risk and Estrangement," Violence and Victims, Vol. 8, No. 1 (1993), 3-16. 
Wrangham, Richard and Dale Peterson, Demonic Males: Apes and the Origins of Human Violence, London: Bloomsbury, 1996.

Yoshikawa, Hirokazu and Elisa A. Rosman, "A Research Agenda for Primary Prevention of Domestic Violence Prepetration in Young Adulthood," mimeo, New York University, 2002. 
Appendix: A Necessary but Uninformative Quadratic

It is convenient to write the function $\mathrm{G}(\pi)$ in a form sufficiently general to accommodate assortative mating as well as divorce:

$$
G(\pi)=A \pi^{2}+B \pi(1-\pi)+C(1-\pi)^{2}+D \pi+E
$$

or, equivalently

$$
G(\pi)=a \pi^{2}+b \pi+c
$$

where

$$
\begin{aligned}
& a=A-B+C \\
& b=B-2 C+D \\
& c=C+E .
\end{aligned}
$$

From the quadratic formula:

$$
\pi *=\frac{-b \pm \sqrt{b^{2}-4 a c}}{2 a}
$$

The existence argument implies that $b^{2}-4 a c \geqq 0$ so that the quadratic has real roots. The uniqueness argument implies that if the roots are distinct, one and only one of them lies in the interval $[0,1]$.

In the absence of assortative mating, $\mathrm{D}=-1$ and $\mathrm{E}=0$, so

$$
\begin{aligned}
& a=A-B+C=s_{v} p_{v}-s_{v} p_{\nabla}-s_{\nabla} p_{v}+s_{\nabla} p_{\bar{v}} \\
& b=B-2 C-1=s_{v} p_{\nabla}+s_{\nabla} p_{v}-2 s_{\nabla} p_{\nabla}-1 \\
& c=C=s_{\nabla} p_{\nabla} .
\end{aligned}
$$


Fig. 1 -- Long-Run Equilibrium.

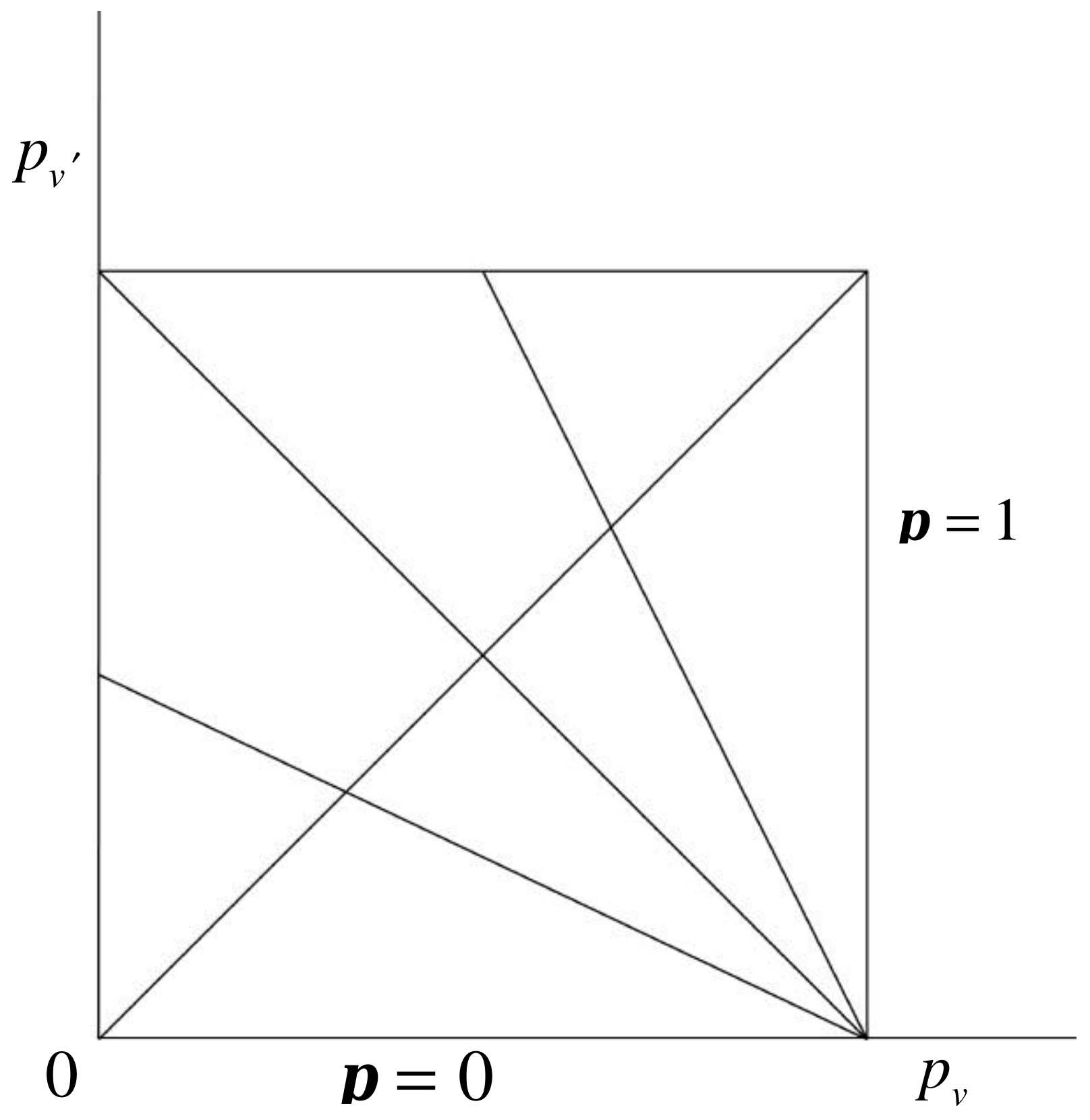


Fig. 2 -- Existence and Uniqueness of Long-Run Equilibrium.

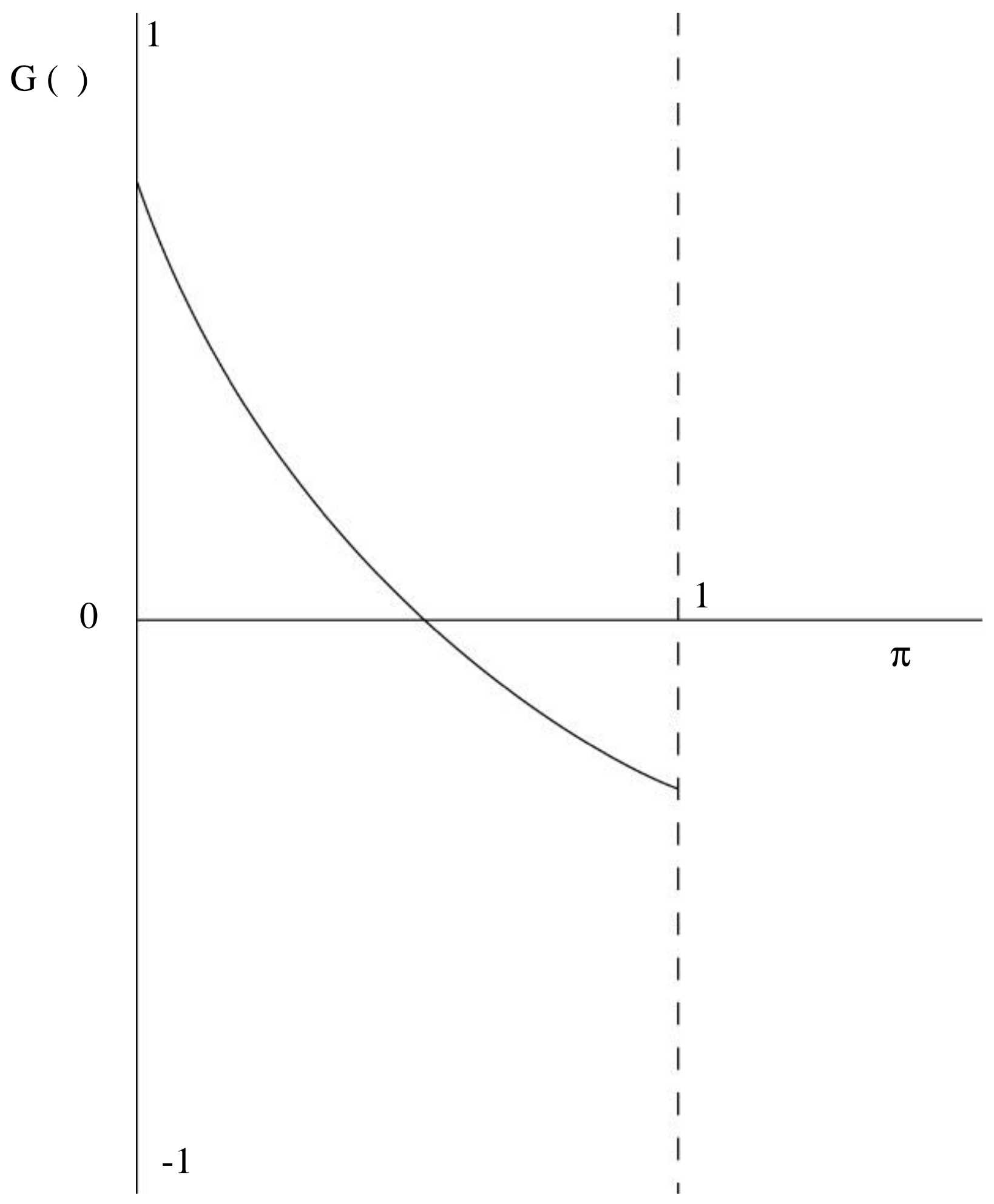

